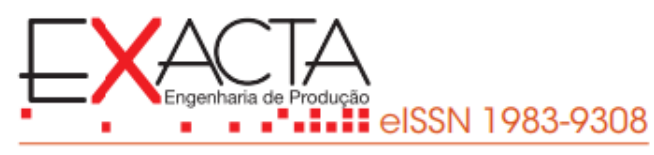

\title{
AVALIAÇÃO DE DESEMPENHO DA LOGÍSTICA REVERSA NO SETOR DA CONSTRUÇÃO CIVIL
}

\section{PERFORMANCE EVALUATION OF REVERSE LOGISTICS IN THE CIVIL CONSTRUCTION SECTOR}

Recebido em: 11 set. 2018

Aprovado em: 07 mar. 2019

Versão do autor aceita publicada online: 07 mar. 2019

Publicado online: 12 maio 2021

\section{Como citar esse artigo - American Psychological Association (APA):}

Hammes, G., Souza, E. D. De, \& Rodriguez, C. M. T. (2021, jul./set.). Avaliação de desempenho da logística reversa no setor da construção civil. Exacta. 19(3), 497-522.

https://doi.org/10.5585/exactaep.2021.10486.

Submeta seu artigo para este periódico $\beta$

Dados Crossmark 


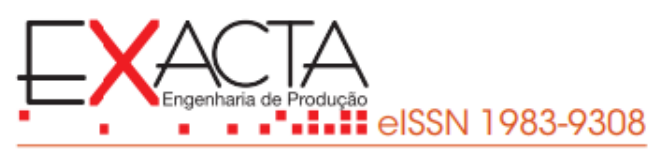

\title{
AVALIAÇÃO DE DESEMPENHO DA LOGÍSTICA REVERSA NO SETOR DA CONSTRUÇÃO CIVIL
}

\author{
PERFORMANCE EVALUATION OF REVERSE LOGISTICS IN THE CIVIL \\ CONSTRUCTION SECTOR
}

\section{Gabriela Hammes ${ }^{1}$ \\ Eduarda Dutra de Souza² \\ Carlos Manuel Taboada Rodriguez ${ }^{3}$}

Recebido em: 11 set. 2018

Aprovado em: 07 mar. 2019
Resumo: A logística reversa é uma atividade logística que prima por agregar valor aos clientes por meio do retornar do produto do consumidor até sua origem. Esse fluxo reverso, quando aplicado para produtos no fim da sua vida útil, torna a logística reversa uma medida ambientalmente correta, pois proporciona uma destinação correta dos resíduos, o que facilita o reuso de material, reciclagem e remanufatura, e, assim, diminui o impacto ambiental. Devido a isso, o presente artigo apresenta um modelo próprio para a avaliação de desempenho desta importante atividade no setor da construção civil - um dos setores que mais gera resíduos e que tem grande impacto econômico no país. A construção deste modelo deu-se por três etapas: (i) a primeira pela revisão da literatura para encontrar lacunas, definir os itens a serem avaliados, (ii) a segunda etapa foi a análise da literatura, a criação dos indiciadores e a confecção do modelo, (iii) por fim, foi realizado um estudo de caso. O modelo elaborado aborda a logística interna, externa e gestão de resíduos afim de avaliar o desempenho da logística reversa nas empresas deste setor. O modelo foi aplicado por meio de um estudo de caso em uma construtora consolidada na capital de Santa Catarina. Além disso, o presente artigo aponta lacunas de pesquisas futuras.

Palavras-chave: Logística Reversa. Construção Civil. Avaliação de desempenho.

Abstract: Reverse logistics is a logistics activity that prizes for adding value to customers by returning from the consumer product to its origin. This reverse flow, when applied to products at the end of their useful life, makes reverse logistics an environmentally correct measure, since it provides a correct disposal of the waste, which facilitates reuse of material, recycling and remanufacturing, and thus reduces the environmental impact. Due to this, the present article presents a model for evaluating the performance of this important activity in the construction sector - one of the sectors that generates the most waste and which has great economic impact in the country. The construction of this model took three steps: (i) the first one to review the literature to find gaps, define the items to be evaluated, (ii) the second stage was the literature analysis, the creation of the indicators and the confection of the model, (iii) finally, a case study was carried out. The elaborated model deals with internal, external logistics and waste management in order to evaluate the performance of reverse logistics in companies in this sector. The model was applied by means of a case study in a consolidated construction company in the capital of Santa Catarina. In addition, this article points to gaps in future research.

Keywords: Reverse logistic. Construction. Performance evaluation. 
1 Introdução

As mudanças climáticas e o esgotamento de matérias primas proporcionaram um processo de conscientização ambiental nas organizações empresariais por uma busca de produtos e processos considerados ambientalmente corretos. Historicamente, o estudo e a gestão da poluição industrial tem sido um problema crítico para a sociedade (Sarkis, Zhu \& Lai, 2011) gerando assim uma preocupação com a aplicação de soluções ambientalmente corretas.

A abordagem mais verde está presente em todos os processos inclusive na logística, que busca organizar e distribuir de forma direta o transporte, armazenagem, embalagem e o gerenciamento de estoque desde o produtor até o consumidor (Rodrigues, Slack \& Comtois, 2001). A Logística Reversa (LR) é uma forma de abordar soluções verdes no processo logístico por se tratar de um complexo sistema de retorno do produto a origem. Este retorno possibilita a reciclagem, reutilização e remanufatura de produtos, e proporciona, ainda, uma melhoria no desempenho ambiental da empresa de forma geral (Carter \& Ellram, 1988). Devido a isso, é necessário que a LR seja bem planejada, executada e controlada, entretanto raramente a literatura discute sobre o seu desempenho. Butzer, Schötz, Petroschke e Steinhilper (2017) afirmam que não é possível administrar eficientemente as cadeias de fornecimento reversas sem avaliar o seu desempenho. Segundo Shaik e Abdul-Kader (2011), poucas medidas são desenvolvidas para avaliar o desempenho da LR.

Desta forma, é necessário que se conduzam pesquisas a respeito da avaliação de desempenho da LR. Conforme Bouzon, Govidan e Rodriguez (2016), a LR ainda está em estágio inicial nos países em desenvolvimento como o Brasil, e a deficiente estrutura logística do país é um dos principais desafios para a implantação desta prática. Assim, se faz necessário investimentos em aplicações que buscam o melhoramento do desempenho da LR.

Apesar de toda essa preocupação, as pesquisas sobre os benefícios da LR não se tornaram comuns no setor da construção civil, permanecendo muito limitado nesse campo (Chilieshe; Rameezdee, Hosseinei \& Lehmann,2015). Isso se deve a presença de algumas barreiras que dificultam o sucesso desta prática, onde surge a necessidade de priorizar o entendimento destas barreiras e soluções para enfrenta-las (Prakash; Barua \& Pandya, 2015). No Brasil, percebe-se que as principais barreiras são o investimento financeiro e questões legais como falta de incentivos fiscais e legislação no país (Souza; Hammes \& Rodriguez, 2017).

A construção civil é um dos setores considerados prioritários da European Comission (2017) pois, em termos de volume, está entre as maiores fontes de resíduos na Europa. Entretanto, muitos dos seus materiais são recicláveis ou podem ser reutilizados por meio da LR. No Brasil, o setor de construção vem refreando a recuperação econômica brasileira em frente à crise econômica, onde o PIB da construção caiu 6,6\% no primeiro semestre de 2017 comparado com o mesmo período de 2016 
(Alvarenga, 2017). Isso demonstra a necessidade de melhorias no setor, onde o lado ambiental pode ser uma forma de impulsionar esse crescimento.

Para atender a exigências legislativas e de seus clientes, as construtoras buscam por certificações e selos ambientais designados para este setor. Essa busca pode ser auxiliada por serviços de consultoria e monitoradas através de auditorias. A avaliação de desempenho contribui para determinar metas, indicadores e organizar a coleta de dados para que assim ocorram as certificações, a elaboração de relatórios e melhoria continua das atividades.

O presente artigo busca responder à pergunta de pesquisa "como avaliar a LR na construção civil?" para solucionar esta indagação, o objetivo principal é propor um modelo de avaliação da LR em empresas típicas do setor de construção por meio da realização de objetivos específicos como: mapear modelos de avaliação da LR na literatura, construir um modelo próprio e aplicar o mesmo em uma empresa do ramo da construção civil. Esse modelo tem como intuito auxiliar as construtoras brasileiras a medirem seu desempenho logístico reverso baseado nos principais selos ambientais para já auxiliar as organizações que desejam implementar as certificações. O modelo foi aplicado em uma empresa consolidada no mercado catarinense para demonstrar a sua aplicabilidade. Assim, após esta introdução encontra-se o referencial teórico, seguido pelos métodos de pesquisa adotados. A seção quatro apresenta uma breve análise dos documentos encontrados na literatura e, na seção cinco, um modelo para a avaliação da LR da construção civil é proposto. Na seção seis o modelo é aplicado em uma construtora e a seção sete apresenta as conclusões da pesquisa.

\section{Referencial teórico}

Avaliação de desempenho busca a mensuração das atividades da organização com intuito de melhorar a eficiência e eficácia da operação. De acordo com Neely, Gregory e Platts (2005, p. 1228) a medição de desempenho "é o processo de quantificação de ação, onde a medição é o processo de quantificação e a ação é que leva ao desempenho". Isto é, a medição de desempenho é fundamental para saber se uma atividade é realizada de forma eficiente e se há necessidade de realizar medidas corretivas (Singh \& Acharya, 2014).

Na logística, responsável por colocar as mercadorias no lugar e no instante correto, nas condições desejadas e ao menor custo possível (Ballou, 1993), Shaik e Abdul-Kader (2011) apontam motivos os quais as empresas investem em um sistema de medição do desempenho nessa área, como:

- Obter uma visão holística do processo de logística;

- Acompanhar o desenvolvimento de atividades de logística ao longo do tempo;

- Uma melhor compreensão do que está acontecendo;

- A possibilidade de influenciar comportamentos; 
- Obter resultados competitivos;

- Compreender as competências exclusivas das empresas;

- Uma melhor alocação e controle de recursos;

- Identificação de ineficiências e redução de custos;

- Melhoria do serviço ao cliente;

- Descoberta de serviços de valor adicionado para o qual os clientes estariam dispostos a pagar; e

- Melhoria de processos.

A aplicação da avaliação de desempenho na LR busca medir a eficiência a e a eficácia das atividades envolvidas no fluxo reverso de materiais com o intuito de avaliar se estas atividades podem ser melhoradas e onde pode-se investir mais recursos para aumentar os seus benefícios. Ser eficaz em uma cadeia é fazer a coisa certa (Crawford \& Bryce, 2003). Assim, uma cadeia de suprimentos reversa gerida com eficácia possibilita a descoberta de lucros escondidos e uma melhor satisfação dos clientes (Badenhorst, 2013). Já a eficiência, de acordo com Crawford e Bryce (2003), gerencia os custos, os processos e o uso correto do capital humano, financeiro e natural, ou seja, eficiência é fazer certo as coisas. Desta forma, uma cadeia de suprimentos eficiente e bem gerenciada pode melhorar a posição competitiva da organização e resultar em economia de custos em transporte, estoques e eliminação de resíduos (Badenhorst, 2013).

Isto é, não adianta fazer a coisa certa e fazer certo as coisas se a organização não monitorar o desempenho das atividades envolvidas no fluxo reverso. A LR é definida por Rogers e Tibben-Lembke (1999, p. 2) como:

O processo de planejamento, implementação e controle do fluxo eficiente e de baixo custo de matérias primas, estoque em processo, produto acabado e informações relacionadas, desde o ponto de consumo até o ponto de origem, com o propósito de recuperação de valor ou descarte apropriado para coleta e tratamento de lixo.

Isto é, um processo básico de LR compreende as seguintes atividades: coleta, inspeção, classificação, desmontagem e disposição (Badenhorst, 2013). A LR pode ser subdividida em duas: pósvenda e pós-consumo. Denominaremos de LR de Pós-Venda a área responsável por agregar valor ao produto devolvido por razões tais como erros no processamento dos pedidos, garantia, defeitos ou falhas (Leite, 2002). Já o Pós-Consumo refere-se a agregar valor a um produto no fim da sua vida útil que possua alguma funcionalidade através dos recursos de reuso, desmanche, reciclagem, remanufatura e reutilização (Leite, 2002).

As atividades de gerenciamento e reciclagem de resíduos estão ligadas a regulamentações ambientais e muitos países estão empenhando-se em melhorar a eficiência nesta área. Devido a isso, 
surgiu o conceito de cadeias de suprimento de ciclo fechado, que combinam a logística tradicional com a reversa para enquadra-se nas conformidades das políticas públicas (Trochu; Chaabane \& Ouhimmou, 2018).

Na construção civil, a busca por construções ambientalmente responsáveis e eficientes ao longo de todo ciclo de vida incentiva o uso mais efetivo e eficiente da energia, água e dos materiais utilizados como forma de garantir a minimização do efeito ambiental (Akdag \& Beldek, 2017). Atualmente, o setor é responsável por aproximadamente 50\% dos recursos naturais extraídos na natureza (CBCS, 2014). No Brasil, percebe-se que até 2002 não havia políticas públicas que se preocupam com os resíduos gerados pelo setor da construção civil (Schneider \& Philippi Jr, 2004), tornando o problema ainda maior. Hoje existe a Resolução Conama n. 307/2002, o qual apresenta diretrizes para a gestão de resíduos de construção civil (CBCS, 2014).

Na questão dos resíduos, o Conselho Brasileiro de Construção Sustentável - CBCS aborda três tipos de materiais: fabricação, uso e pós-uso. Dentro da Fabricação, as grandes empresas brasileiras adotam a certificação ISO 14000 e apresentam relatórios de responsabilidade socioambiental. Na fase do uso, há problemas com a lixiviação de espécies perigosas de materiais e utilização de tintas por apresentarem caráter toxico. Por fim, os resíduos de pós-uso têm como característica que grande parte retorna para natureza em curto período de tempo, por exemplo, a produção do alumínio já que para gerar $1 \mathrm{~kg}$ do produto, são extraídos e utilizados $5 \mathrm{~kg}$ de bauxita como matéria-prima, isto é, grande parte do resíduo é gerado antes da fase de uso do produto (CBCS, 2014).

Além disso, é necessário preocupar-se com a Sustentabilidade em todas as etapas do ciclo de vida da construção, desde a concepção, projeto, construção, manutenção e sua demolição (Esin \& Cosgun, 2007). Isto é, a indústria da construção civil deve administrar desde o projeto de construção até a demolição do mesmo considerando não apenas estética e o uso do edifício, mas também a eficiência dos recursos utilizados (Akdag \& Beldek, 2017). Devido a esse cenário, as organizações precisam começar a aplicar medidas mais ambientalmente corretas, por isso há necessidade de compreender os benefícios da implementação destas medidas. A Tabela 1 apresenta as principais vantagens. 


\section{Tabela 1}

Benefícios das Práticas Ambientais Aplicadas na Construção Civil

\begin{tabular}{|c|c|c|}
\hline Benefícios & Descrição & Autor \\
\hline $\begin{array}{l}\text { Redução do consumo de } \\
\text { recursos naturais não- } \\
\text { renováveis }\end{array}$ & $\begin{array}{l}\text { Por meio da aplicação das técnicas de } \\
\text { reciclagem, que auxiliam na redução dos } \\
\text { consumos naturais }\end{array}$ & John (2000) \\
\hline $\begin{array}{l}\text { Redução das áreas destinadas } \\
\text { para aterro }\end{array}$ & $\begin{array}{l}\text { Devido a diminuição do volume de materiais } \\
\text { utilizados, pois há mais aplicação da reciclagem. } \\
\text { Os resíduos de construção e demolição } \\
\text { representam mais de } 50 \% \text { da massa dos } \\
\text { resíduos sólidos urbanos }\end{array}$ & Pinto (1999) \\
\hline $\begin{array}{l}\text { Redução do consumo de } \\
\text { energia durante o processo } \\
\text { de produção }\end{array}$ & $\begin{array}{l}\text { A Indústria do cimento usa resíduos para a } \\
\text { obtenção de sua matéria-prima (co- } \\
\text { incineração). A escória de alto-forno usa } \\
\text { resíduo com composição semelhante ao } \\
\text { cimento }\end{array}$ & John (2000) \\
\hline Redução da poluição & $\begin{array}{l}\text { A indústria de cimento, que reduz a } \\
\text { emissão de gás carbônico utilizando escória de } \\
\text { alto forno em substituição ao } \\
\text { cimento portland }\end{array}$ & John (1999) \\
\hline
\end{tabular}

Fonte: Adaptado de Angulo; Zordan \& John (2001).

Devido a isso, percebe-se que a incorporação das práticas de sustentabilidade é uma tendência crescente no mercado (Corrêa, 2009). A sustentabilidade é o equilíbrio de três pilares: social, ambiental e econômico, criado por Elkington (1994) e conhecido pelo termo triple bottom line. A LR encontra-se presente dentro dos três pilares como uma forma de diminuir impactos ambientais e sociais para a sociedade, e diminuir custos para as empresas por meio da venda de resíduos e reutilização de materiais.

No setor de construção civil, a literatura apresenta quatro principais barreiras: o ambiente regulatório, os custos adicionais envolvidos, falta de reconhecimento na cadeia de suprimentos da construção e esforço extra necessário (Chilieshe et al.,2015). Os principais selos verdes presentes atualmente são:

- Selo LEED (Leadership in Energy and Environmental Design): é considerado uma das principais certificações de edifícios verdes do mundo, concedido pelo Green Building Council, o qual, avalia oito dimensões da obra, entre elas a localização e transporte, sustentabilidade do local e os materiais e recursos utilizados (Leed, 2018). Além disso, esse selo é considerado flexível e pode 
ser adaptado para cada tipo de construção e trabalha o ciclo de vida do empreendimento (Valente, 2009).

- SELO AQUA - HQE: Desenvolvido posterior ao RIO92 por meio da certificação francesa Démarche HQE (Haute Qualité Environnementale) leva em consideração 14 categorias. De acordo com o Processo Aqua (2016), entre as categorias encontra-se a gestão de resíduos de uso e operação do edifício, a escolha integrada de produtos, sistemas e processos construtivos e o canteiro de obras de baixo impacto ambiental.

- Selo Casa Azul: é uma classificação socioambiental de empreendimentos residenciais da Caixa Econômica Federal, o primeiro sistema de certificação criado para a realidade da construção habitacional brasileira (Grunberg; Medeiros \& Tavares, 2014). Esse selo, avalia o desempenho ambiental de uma construção por meio da sua natureza arquitetônica e técnica, além da sua gestão. Estrutura-se em 6 categorias: Qualidade urbana; projeto e conforto; eficiência energética; conservação de recursos materiais; gestão da água; e práticas sociais (John \& Prado, 2010).

\section{Método}

O procedimento metodológico do presente artigo é dividido em três etapas conforme apresentado na Figura 1. A primeira etapa refere-se a pesquisa na literatura para aprofundamento do assunto; na segunda etapa ocorre a confecção do modelo proposto pelos autores; e a terceira etapa demonstra a aplicabilidade do modelo por meio de um estudo de caso simplificado. 
Figura 1

Etapas metodológicas da pesquisa

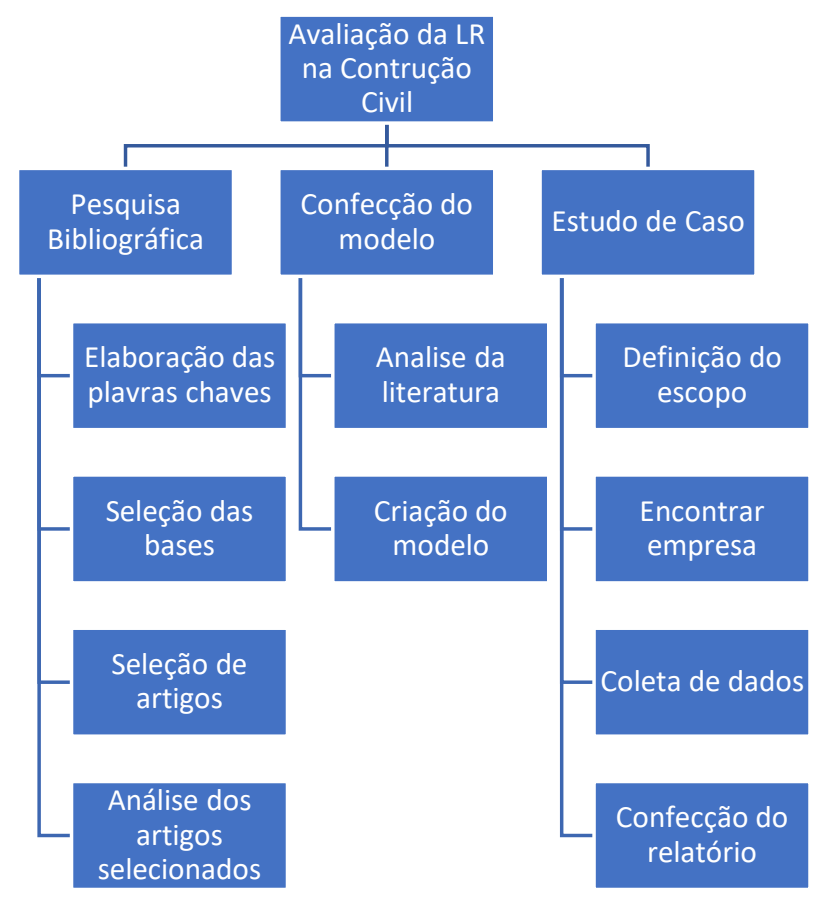

Fonte: Os autores.

A primeira etapa iniciou-se com uma busca bibliográfica nas bases de dados a procura de trabalhos publicados em revistas de alto impacto. Utilizou-se dois eixos na língua inglesa, por conter maior número de retornos nesta língua. O primeiro eixo aborda a LR ("reverse logistic *") e o segundo a avaliação de desempenho ("performance evaluation" OR "performance assessment" OR "performance measurements" OR "evaluation of logistics performance" OR "performance evaluation"). As palavraschave foram testadas em uma busca preliminar realizada no Portal de Periódicos da CAPES (Coordenação de Aperfeiçoamento de Pessoal de Nível Superior), onde foi possível identificar as bases de dados com maior número de resultados para a busca, que são: Scopus, Science Citation Index Expanded (Web of Science), ProQuest, OneFile (GALE) e Science Direct, onde as duas últimas não encontraram nenhum resultado. A busca resultou em um total de 157 artigos. Após uma seleção, que pode ser melhor restaram 39 artigos que tratam sobre a avaliação de desempenho na LR.

Posteriormente focou-se a pesquisa no setor de construção civil, com intuito de fundamentar os resultados do presente artigo. Utilizou-se a base de dados Scopus por apresentar o maior retorno de publicações sobre o assunto. Utilizando os termos referentes a construção civil e LR, criou-se o comando de pesquisa ("construction industry" OR "construction market" OR "building sector" OR "building construction") AND ("reverse logistic*") para detectar os artigos publicados na área. A pesquisa resultou em 27 documentos, dos quais, após uma seleção, 19 artigos foram lidos na integra. Após a busca nas 
bases de dados, foi realizada uma análise descritiva do cenário de publicações (apresentado no Tópico 4 desta pesquisa) e justificativa para o modelo elaborado no capítulo Resultados.

A segunda etapa do artigo é o desenvolvimento do modelo proposto com base na literatura, onde não foram encontradas métricas para medir o desempenho da LR. Os artigos selecionados apenas apresentam os pontos a serem avaliados e, a partir disso, foi possível criar indicadores para avaliar a LR da construção civil. O modelo foi dividido em três áreas, onde apresenta cinco indicadores para a logística externa a empresa; três indicadores para a logística interna; e 4 indicadores para a gestão de resíduos. As certificações ambientais presentes no setor também serviram como base para a construção dos indicadores do modelo. O desenvolvimento do trabalho e o modelo elaborado são apresentados no Tópico 5 deste trabalho.

Por fim, na última etapa é apresentado um estudo de caso realizado em uma construtora. Este método coleta informações sem interferir no funcionamento da empresa e proporciona uma visão geral do problema (Miguel; Fleury; Mello; Nakano; Lima; Turrioni; Ho; Morabito; Martins; Sousa; Costa \& Pureza, 2012). O estudo de caso desenvolveu-se com a definição do escopo teórico, a partir de publicações científicas, como explanado anteriormente, na busca por pesquisas que abordam o tema. A partir do escopo teórico o modelo para avaliação da LR da construção civil foi proposto. Em seguida o caso foi planejado, onde buscou-se por uma empresa do setor da construção civil e uma visita foi marcada. A empresa selecionada possui mais de 30 anos de atuação na construção de mais de 100 edifícios residenciais e comerciais de alto padrão na região da Grande Florianópolis, sob o selo de qualidade ISO 9001 e PBPQH nível A. Atualmente conta com dois edifícios residenciais em construção, nos quais realiza a gestão dos seus resíduos e retorno dos materiais quando possível.

A coleta de dados aconteceu por meio de uma visita a empresa e conversa com os gestores, que disponibilizaram as informações necessárias para o cálculo dos indicadores. Em seguida os dados foram analisados pelos gestores da empresa e por pesquisadores da área. Por fim, um relatório foi gerado, o que resultou nesta presente pesquisa. Os resultados do estudo de caso são apresentados no tópico 6 deste presente artigo.

\section{Análise bibliográfica}

A fim de compreender o cenário atual de publicações a respeito da avaliação de desempenho na LR, realizou-se uma análise dos resultados da base de dados Scopus a partir do software VOSviewer. A Figura 2 apresenta uma análise de 56 artigos publicados em journals, eventos, reviews, capítulos de livro e outros tipos de documentos científicos. 
Figura 2

Palavras-Chave Mais Utilizadas nos Documentos Encontrados na Busca Bibliográfica Sobre Avaliação de Desempenho e Logística Reversa

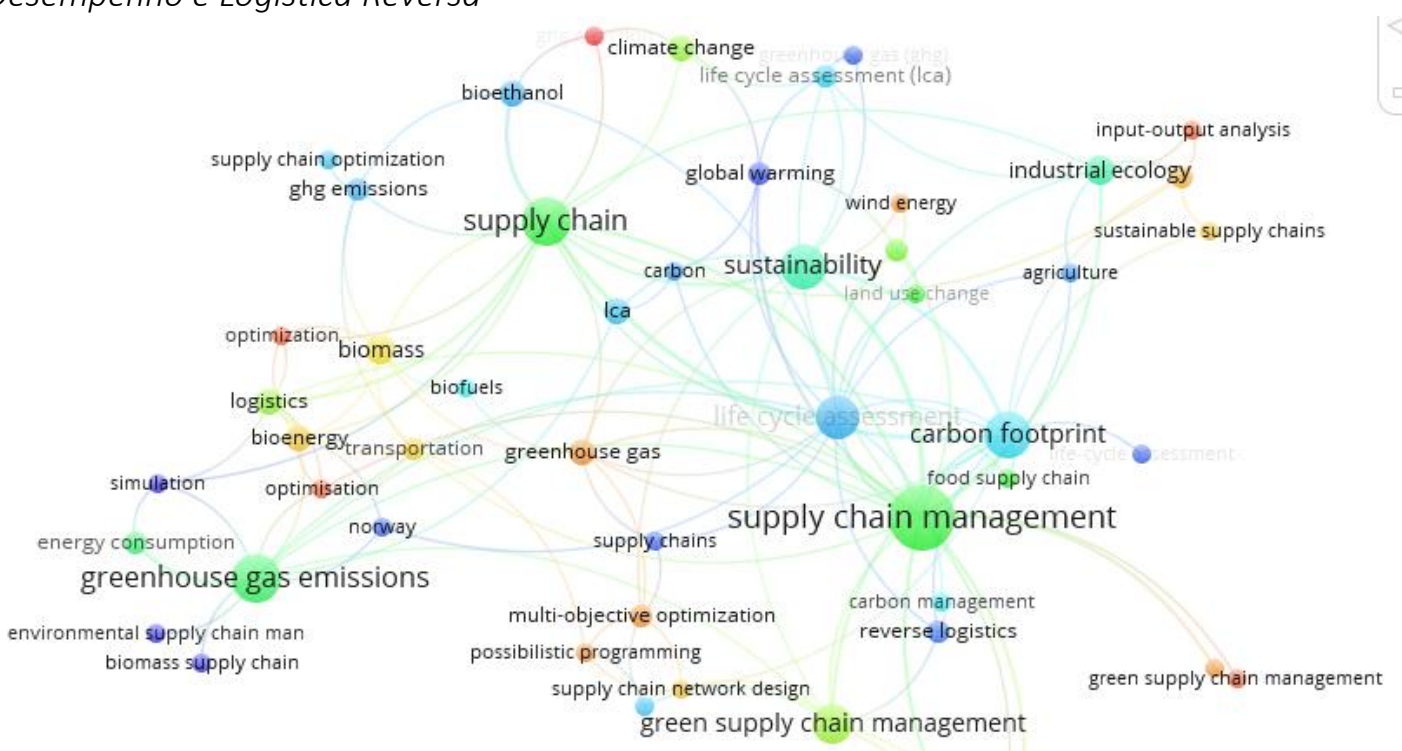

Fonte: VOSviewer.

aggregate production planning

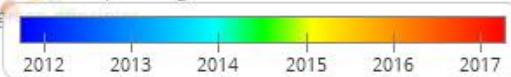

Percebe-se que atualmente as palavras-chaves mais utilizadas são termos como "optimization", "green supply chain management", "GHG emission", "input output". No ano de 2016, destacou-se palavras como "ecology", "sustainable supply chain", "bioenergy", "biomass" e "greenhouse gas".

Ao analisar os 19 artigos que retratam a situação na construção civil, percebeu-se que as publicações estão concentradas a partir do ano de 2015, onde os países com maior número de publicações são: Austrália (5), Brasil (4), Grécia (2), Turquia (2) e Reino Unido (2). Esses artigos concentram sua pesquisa em barreiras para implementação e Green Supply Chain. Os artigos nacionais abordam a indústria de construção, revisão da literatura, gerenciamento de resíduos de edifícios e localização de instalações para destinação de resíduos sólidos da construção civil. Percebeu-se que não foram encontradas publicações de estudos que buscam avaliar o desempenho da LR na construção civil brasileira.

O tema ainda é justificado com a análise das palavras-chaves de cada artigo por meio do software VOSviewer, na Figura 3, o qual, apresenta a disposição dessa classificação ao longo dos anos. A tonalidade inicia-se na azul com os artigos anteriores a 2010 e vai tornando-se vermelha para os artigos mais recentes. 
Figura 3

Palavras-Chave Mais Utilizadas nos Documentos Encontrados na Busca Bibliográfica Sobre Construção Civil e Logística Reversa

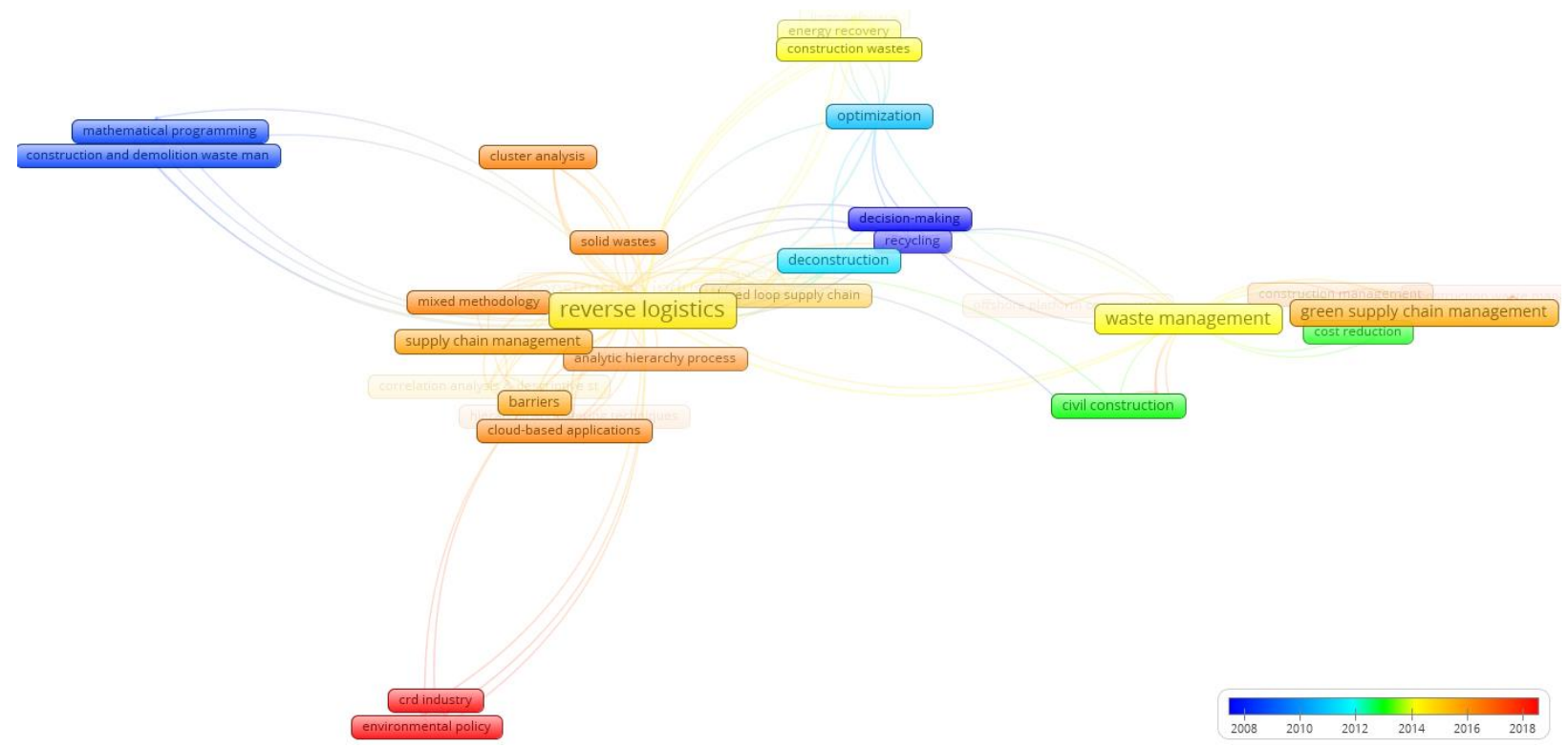

Fonte: VOSviewer.

Atualmente estão se estudando politicas ambientais e a relação dos impostos com a industria da constução e meio ambiente. Isso ocorre pois a prática da avaliação de desempenho auxilia aos gestores e fiscais a compreender o estado atual da organização. A sua aplicação na LR torna-se uma forma de avaliar essa prática verde no setor da construção civil.

\section{Modelo proposto}

O modelo aqui apresentado leva em consideração apenas os pontos presentes na LR e foi subdivido em três tópicos: o primeiro leva em consideração as atividades de logística externas a empresa; o segundo aborda as atividades de logística interna a empresa; e o terceiro apresenta indicadores para a gestão de resíduos. Cada um destes pontos é subdivido em indicadores e a média destes indicadores resulta em um indicador geral para a LR da empresa.

\subsection{Logística externa}

As atividades externas a empresa iniciam-se pelo setor de compras, onde deve-se priorizar produtos que foram projetados segundo os conceitos do eco- design e da LR, visando a sua reciclagem, reutilização, reprocessamento ou o seu descarte. O indicador de compras mostra a porcentagem de 
produtos que seguem estes conceitos e quanto mais próximo de 100\% melhor para as práticas reversas. Os indicadores de transporte consideram o uso eficiente e eficaz do meio de transporte utilizado e, como forma de se adequar as legislações ambientais, criou-se um indicador para a emissão de carbono (CO2). A satisfação dos clientes apresenta a imagem da empresa e a influência destas atividades na competitividade da mesma. Este indicador pode ser medido através de uma pesquisa de satisfação após a entrega do edifício. Entre as diversas perguntas da pesquisa pode-se incluir uma questão envolvendo a LR. Os indicadores para a logística externa são apresentados na Tabela 2.

Tabela 2

Indicadores da Logística Externa

INDICADORES DESCRIÇÃO FÓRMULA

\begin{tabular}{|c|c|c|}
\hline $\begin{array}{l}\text { Compras Verdes } \\
\text { (CV) }\end{array}$ & $\begin{array}{l}\text { Porcentagem de produtos } \\
\text { comprados que facilitam o seu } \\
\text { retorno após utilizados. Quanto } \\
\text { mais próximo de } 100 \% \text { melhor. }\end{array}$ & $\begin{array}{c}\text { Produtos que possibilitam a LR } \\
\text { Total de Produtos } \\
* 100 \%\end{array}$ \\
\hline $\begin{array}{l}\text { Desperdício de } \\
\text { Espaço do } \\
\text { Transporte (DET) }\end{array}$ & $\begin{array}{l}\text { Porcentagem de utilização do } \\
\text { espaço no meio de transporte. } \\
\text { Valores abaixo de } 100 \% \text { indicam } \\
\text { desperdício de espaço. }\end{array}$ & $\begin{array}{c}\frac{\text { Volume de material transportado }}{\text { Capacidade do caminhão }} \\
* 100 \%\end{array}$ \\
\hline $\begin{array}{l}\text { Desperdício de } \\
\text { Material em } \\
\text { Transporte (DMT) }\end{array}$ & $\begin{array}{l}\text { Porcentagem de desperdício de } \\
\text { material durante o transporte. } \\
\text { Valores abaixo de } 100 \% \text { indicam } \\
\text { desperdício de materiais. }\end{array}$ & $\begin{array}{c}\text { Volume que saiu da obra } \\
\text { Volume que che gou ao destino } \\
* 100 \%\end{array}$ \\
\hline $\begin{array}{l}\text { Emissão } \\
\text { Carbono (EC) }\end{array}$ & $\begin{array}{l}\text { Emissão de carbono nos } \\
\text { transportes de acordo com a } \\
\text { quilometragem rodada e o fator } \\
\text { de emissão presente na Tabela } 4 .\end{array}$ & $\begin{array}{l}\text { Quilometragem rodada * fator de emissão do } \\
\text { combustível por quilometro }\end{array}$ \\
\hline $\begin{array}{l}\text { Satisfação } \\
\text { Cliente (SC) }\end{array}$ & $\begin{array}{l}\text { Porcentagem de respostas } \\
\text { positivas na pesquisa de } \\
\text { satisfação dos clientes (A gestão } \\
\text { de resíduos impacta na sua } \\
\text { escolha de compra?) }\end{array}$ & $\frac{\text { Respostas positivas }}{\text { Total de respostas }} * 100 \%$ \\
\hline
\end{tabular}

Fonte: Os autores.

O indicador de Emissão de Carbono (EC) envolve o fator de emissão de acordo com o combustível utilizado. Este fator pode ser observado na Tabela 3. 
Tabela 3

Fator de Emissão de $\mathrm{CO} 2$ dos Combustíveis

\begin{tabular}{llll} 
Gasolina & Etanol & Diesel & Gás Natural (GNV) \\
\hline $0,227 \mathrm{kgCO} 2 / \mathrm{Km}$ & $0,176 \mathrm{kgCO} 2 / \mathrm{Km}$ & $0,445 \mathrm{kgCO} 2 / \mathrm{Km}$ & $0,286 \mathrm{kgCO} 2 / \mathrm{Km}$
\end{tabular}

Fonte: Adaptado de Cancelli e Dias (2014).

O indicador de EC deve ser o menor possível e não entra no cálculo do indicador geral da LR, para que, assim, facilite a aplicação de todos os tipos e tamanhos de empresas da indústria de construção civil. Desta forma, o indicador final de logística externa é calculado segundo a Equação 1.

$$
L E=\frac{C V+D E T+D M T+S C}{4}
$$

\subsection{Logística interna}

Durante a utilização dos materiais pode ocorrer desperdícios, que também são medidos pois podem acabar gerando um volume maior de resíduos do que o planejado. A logística interna aborda o desperdício de materiais e a reutilização de matérias nos processos que acontecem dentro da empresa e os custos envolvidos. Um exemplo da reutilização de materiais é a madeira utilizada nas formas para a concretagem, que pode ser reutilizada nas concretagens posteriores. Outro exemplo seria as escoras, que podem ser utilizas mais de uma vez. O modelo também calcula o retorno do capital investido nas atividades de LR ao longo do tempo. Os indicadores para a logística interna estão expostos na Tabela 4. 
Tabela 4

Indicadores da Logística Interna

INDICADORES

DESCRIÇÃO

FÓRMULA

\begin{tabular}{|c|c|c|}
\hline $\begin{array}{l}\text { Aproveitamento } \\
\text { de Materiais } \\
\text { (AM) }\end{array}$ & $\begin{array}{l}\text { Porcentagem de aproveitamento } \\
\text { de materiais: } \\
\text { 100\%: todos os materiais são } \\
\text { aproveitados. } \\
\text { Maior que 100\%: Houve erro no } \\
\text { cálculo de quantidade de } \\
\text { materiais ou desperdício } \\
\text { (necessita averiguação) } \\
\text { Menor que 100\%: Existe } \\
\text { desperdício de materiais pois o } \\
\text { consumo foi maior que o } \\
\text { planejado. }\end{array}$ & $\frac{\text { Materiais consumidos }}{\text { Materiais planejados }} * 100 \%$ \\
\hline $\begin{array}{l}\text { Reutilização de } \\
\text { Materiais (RM) }\end{array}$ & $\begin{array}{l}\text { Porcentagem de materiais } \\
\text { reutilizados durante a construção. } \\
\text { Quanto mais próximo de } 100 \% \\
\text { maior a reutilização. }\end{array}$ & $\begin{array}{c}\text { Volume de material reutilizado } \\
\qquad \begin{array}{c}\text { Volume de material utilizado } \\
* 100 \%\end{array}\end{array}$ \\
\hline $\begin{array}{l}\text { Retorno de } \\
\text { Investimento (RI) }\end{array}$ & $\begin{array}{l}\text { Porcentagem do retorno de } \\
\text { investimento. }\end{array}$ & $\begin{array}{l}\text { [(Lucro com vendas de resíduos + economia } \\
\text { na compra de materiais que são reutilizados } \\
\text { - capital investido) / Capital investido em LR] } \\
{ }_{1}^{100 \%}\end{array}$ \\
\hline
\end{tabular}

Fonte: Os autores.

O indicador de retorno de investimento é um valor muito relativo. Logo após a implantação da LR este indicador pode resultar em baixas porcentagens, mas ao longo do tempo pode apresentar valores muito superiores a $100 \%$, e não se tem previsão do valor que esta porcentagem pode atingir. 0 indicador geral da logística interna é calculado de acordo com a Equação 2.

$L I=\frac{A M+R M+R I}{3}$

\subsection{Gestão dos resíduos}

Após a utilização são gerados os resíduos, que devem ser armazenados corretamente para que não se estraguem no período em que ali permanecem. Os indicadores de gestão de resíduos, presentes na Tabela 5, englobam as atividades envolvidas no manejo dos resíduos e o envolvimento dos colaboradores nestas atividades. Esta área inclui um indicador relacionado a uma pesquisa com os funcionários para perceber a conscientização dos mesmos quanto a importância do seu trabalho ser 
voltado para a gestão dos resíduos, o que permite a percepção do envolvimento dos funcionários nesta atividade.

Tabela 5

Indicadores de Gestão de Resíduos

INDICADORES

Baias de
Armazenamento
(BA)
Erros de
Armazenamento
(EA)

Porcentagem de resíduos que possuem sua baia individual. Para sua correta destinação é importante que cada tipo de resíduo possua sua baia para ser armazenado. Este indicador mede se todos os resíduos são armazenados individualmente ou não.

Porcentagem de materiais
encontrados em local de armazenagem errado. O " $\mathrm{x}$ " representa o resíduo que deve ser armazenado na baia avaliada e o " $y$ " representa o volume de resíduos diferentes de " $x$ " presentes na baia. Quanto menor esta porcentagem, menor o número de erros.
FÓRMULA

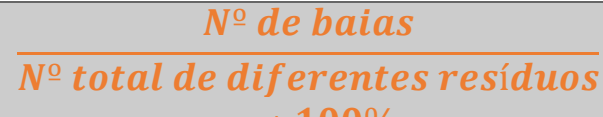

$* 100 \%$ 100\% - Volume de resíduo "y" na baia "x"
Volume total do resíduo "x"
$\mathbb{1 0 0 \%}$

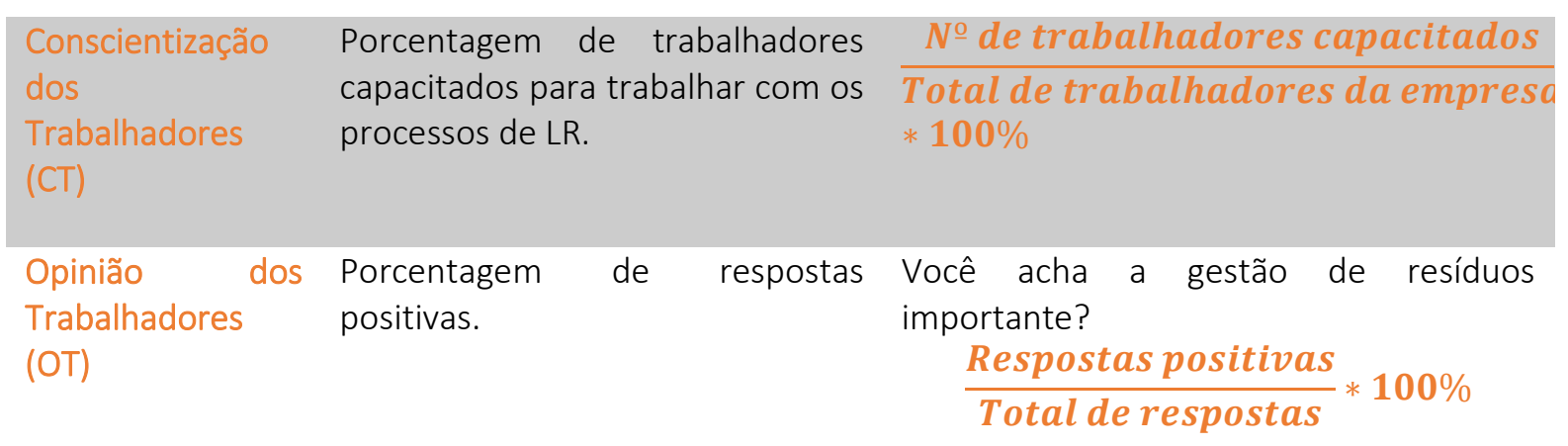

Fonte: Os autores

A porcentagem de materiais encontrados na baia errada deve ser a menor possível, para que não se tenha erros. Os demais indicadores envolvidos na gestão de resíduos possuem seu valor máximo (100\%) como o desejado. Deste modo, é necessário que se subtraia 100\% da porcentagem de materiais encontrados na baia errada (indicador EA), para saber a porcentagem de acertos. A Equação 3 mostra o indicador geral da gestão de resíduos. 


\section{$G R=\frac{B A+E A+C T+O T}{4}$}

\subsection{Indicador geral}

Após o cálculo de todos os indicadores e dos indicadores de cada tópico, é possível calcular um indicador geral para a LR, apresentado na Equação 4 . O indicador geral da LR é uma média simples dos indicadores de cada tópico (LE - Logística Externa; LI - Logística Interna; GR - Gestão de Resíduos). Se sentir necessidade, as empresas podem realizar uma média ponderada e atribuir pesos de acordo com a importância de cada tópico para a empresa.

$$
L R=\frac{L E+L I+G R}{3}
$$

O resultado deste indicador geral avalia a atual situação das LR na empresa. Valores abaixo de 30\% são um alerta para que os gestores deem maior atenção para a LR e criem soluções de melhoria para as atividades reversas. Valores entre $80-30 \%$ indicam uma LR em funcionamento mediano, necessitando de melhorias no seu sistema de atenção por parte dos gestores. Valores acima de 80\% indicam uma LR bem administrada, mas que ainda necessita de acompanhamento e melhoria contínua de seus processos para que este valor não diminua.

\section{Aplicação do modelo}

Os materiais utilizados na construção dos edifícios (matérias-primas) são comprados de seus fornecedores específicos, alguns são armazenados no canteiro central, separados e enviados para a obra onde são requisitados; outros são enviados dos seus fornecedores diretamente para a obra. Ao chegar na obra os materiais são separados e armazenados no almoxarifado. Quando requisitados são enviados para o local de trabalho onde são utilizados. Os resíduos são separados já no local onde são gerados e posteriormente são dispostos em baias construídas no canteiro de obras. Cada material possui uma baia específica: plástico, papel, madeira, gesso, alumínio, cobre, bronze e entulho (quebras). O aço é cortado e montado no canteiro central e enviado pronto para o uso para a obra. Assim, os resíduos de aço ficam armazenados no canteiro central da empresa. Os resíduos de alumínio retornam para seu fornecedor e são revertidos em crédito para a próxima compra. As sobras de material são reutilizadas em outra obra ou na manutenção dos edifícios já entregues. O restante dos resíduos é vendido como matéria-prima para outra indústria, com exceção dos materiais que não possuem mais 
valor de uso (rejeitos), que são enviados para uma empresa responsável pela sua destinação correta ambientalmente. A Figura 4 apresenta o fluxo de materiais da empresa.

Figura 4

Fluxo de Materiais

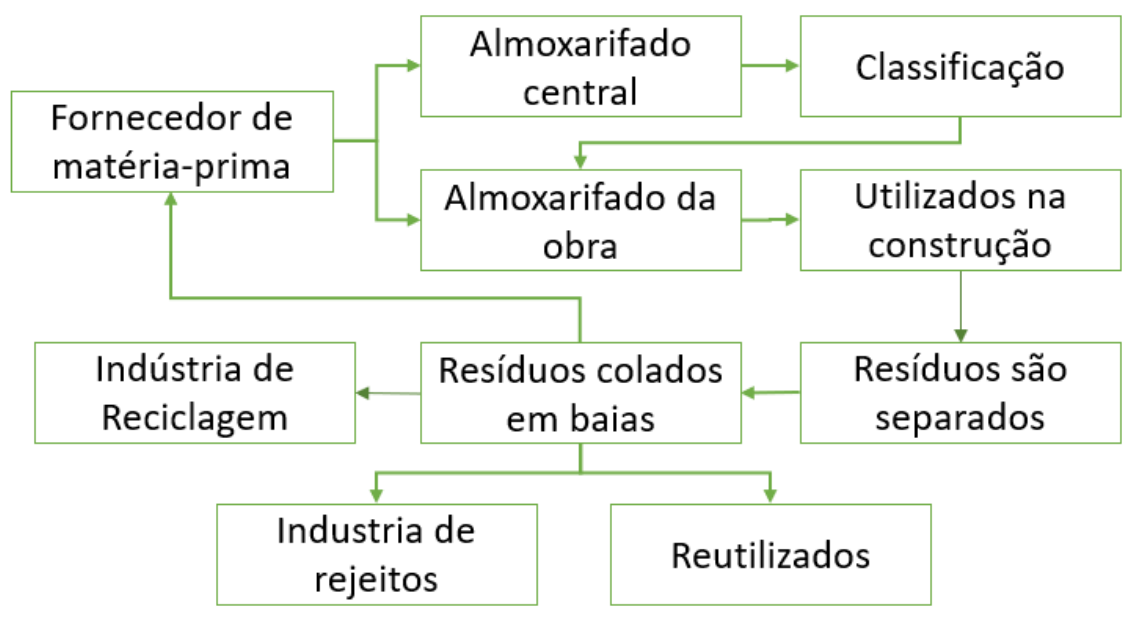

Fonte: Os autores.

O modelo apresentado foi apresentado para gestores da construtora que disponibilizaram os dados para o cálculo dos indicadores para demonstrar a sua aplicabilidade. A aplicação do modelo é apresentada nas Tabelas 6, 7 e 8 a seguir. 
Tabela 6

Aplicação dos Indicadores Para a Logística Externa a Empresa

INDICADORES MEDIDA

DESCRIÇÃO

\begin{tabular}{lll}
\hline CV $0 \%$ & $\begin{array}{l}\text { Envolve o setor de compras, que afirmou não ter uma política } \\
\text { de compras verdes e não tem conhecimento de produtos que } \\
\text { possam facilitar a LR, apesar de existir uma parceria com o } \\
\text { fornecedor de alumínio, que recolhe as sobras do material e } \\
\text { transforma em novos produtos. }\end{array}$ \\
DET $100 \%$ & $\begin{array}{l}\text { O caminhão que transporta os resíduos possui uma } \\
\text { capacidade de } 12 \text { metros cúbicos e é utilizado na sua } \\
\text { capacidade máxima pois os resíduos ficam armazenados na } \\
\text { abro até completar uma carga. }\end{array}$
\end{tabular}

\begin{tabular}{|c|c|c|}
\hline DMT & - & $\begin{array}{l}\text { A empresa não tem controle da quantidade de material que } \\
\text { saiu da obra. Os resíduos são pesados apenas quando } \\
\text { chegam no seu destino. }\end{array}$ \\
\hline EC 1 & $\begin{array}{l}2,1 * 0,445= \\
0,9345 \mathrm{kgCO} 2\end{array}$ & $\begin{array}{l}\text { Emissão de carbono no transporte do aço, do canteiro central } \\
\text { até a empresa de reciclagem, a uma distância de } 2,1 \mathrm{~km} \text {. } 0 \\
\text { caminhão utiliza o diesel como combustível. }\end{array}$ \\
\hline
\end{tabular}

$\begin{array}{ll}\text { EC2 } 2,0 * 0,445= & \begin{array}{l}\text { Emissão de carbono no transporte do alumínio, da obra } \\ 2,67 \mathrm{kgCO} 2\end{array} \\ \text { menos favorável (maior distância) até o fornecedor, a uma } \\ \text { distância de } 6 \mathrm{~km} \text {. O caminhão utiliza o diesel como } \\ \text { combustível. }\end{array}$

Fonte: Os autores. 
Tabela 7

Aplicação dos Indicadores Para a Logística Interna da Empresa

INDICADORES

\begin{tabular}{ll}
\hline AM 100\% & $\begin{array}{l}\text { O cálculo de quantidade de materiais a ser comprado é feito por } \\
\text { uma equipe de engenheiros que leva em consideração os } \\
\text { materiais em estoque (sobra de outras compras) para evitar o } \\
\text { desperdício. }\end{array}$
\end{tabular}

RM
$100 \%$ para

formas de

madeira e

escoras
A madeira utilizada nas formas para a concretagem é reutilizada até o seu fim de vida útil. Um jogo de formas pode ser utilizado durante toda a construção do prédio. As escoras metálicas também são reutilizadas, inclusive em mais obras. Para os demais produtos não se têm dados para o cálculo do indicador.

$\begin{array}{ll}\text { RI R\$4500,00 } & \begin{array}{l}\text { Lucro da venda dos resíduos no ano de 2017. A empresa não tem } \\ \text { controle do capital investido. }\end{array}\end{array}$

Fonte: Os autores.

Tabela 8 - Aplicação dos indicadores para a gestão dos resíduos da empresa

\section{INDICADORES MEDIDA DESCRIÇÃO}

\begin{tabular}{|c|c|c|}
\hline BA & $100 \%$ & $\begin{array}{l}\text { Todos os resíduos possuem a sua baia de armazenamento } \\
\text { individual. }\end{array}$ \\
\hline EA & - & $\begin{array}{l}\text { A empresa não possui controle da quantidade de materiais que } \\
\text { são encontrados na baia errada, mas acontece e vem diminuindo } \\
\text { com o tempo. }\end{array}$ \\
\hline CT & $100 \%$ & $\begin{array}{l}\text { Todos os trabalhadores possuem capacitação interna para } \\
\text { trabalhar com os processos de LR. }\end{array}$ \\
\hline OT & - & Não é realizada pesquisa com os funcionários da empresa. \\
\hline
\end{tabular}

Fonte: Os autores.

Alguns indicadores não foram calculados por falta de informação. Apesar disso, a empresa julga interessante estes indicadores pois fornecem informações importantes a respeito do funcionamento da LR. Dentre os valores disponíveis, descartando os indicadores que não foram calculados por falta de dados, é possível calcular os indicadores da Logística Externa, na Equação 5, da Logística Interna, na Equação 6, e da Gestão de Resíduos na Equação 7. Por fim, o indicador geral é apresentado na Equação 8. 


$$
\begin{aligned}
& \boldsymbol{L E}=\frac{\mathbf{0} \%+\mathbf{1 0 0} \%}{\mathbf{2}}=\mathbf{5 0} \% \\
& \boldsymbol{L I}=\frac{\mathbf{1 0 0} \%+\mathbf{1 0 0} \%}{\mathbf{2}}=\mathbf{1 0 0} \% \\
& \boldsymbol{G} \boldsymbol{R}=\frac{\mathbf{1 0 0} \%+\mathbf{1 0 0} \%}{\mathbf{2}}=\mathbf{1 0 0} \% \\
& \boldsymbol{L} \boldsymbol{R}=\frac{\mathbf{5 0} \%+\mathbf{1 0 0} \%+\mathbf{1 0 0} \%}{\mathbf{3}}=\mathbf{8 3}, \mathbf{3 3} \%
\end{aligned}
$$

\section{Discussões}

Comparando os resultados encontrados com aqueles apresentados na literatura, percebe-se a necessidade em investir em pesquisas no setor de construção civil e na construção de modelos adaptados para o cenário nacional. Nenhum dos selos apresentados no referencial teórico tem foco na gestão de resíduos da empresa/obra, o que demonstra uma dificuldade na aplicação das atividades básicas da LR segundo Badenhorst (2013). Além disso, percebe-se que a literatura aponta a necessidade de cuidar de todo o ciclo da construção desde a concepção, projeto, construção, manutenção e sua demolição (Esin \& Cosgun, 2007). Não foram encontrados dados focados na demolição desses edifícios, sendo um ponto não acompanhado pela empresa estuda. A concepção, projeto e construção são os itens mais abordados por medidas ambientalmente corretas e pelos selos/certificações atuais. Devido a isso, o modelo proposto pelo artigo buscou apresentar indicadores e formas de medir todo o processo.

Os indicadores propostos podem ser utilizados de acordo com o funcionamento de cada empresa e implementados conforme esta vai se adaptando ao modelo e ao funcionamento da sua LR. Por exemplo, muitas empresas terceirizam o transporte de seus resíduos, deste modo os indicadores de transporte não se aplicam. Outras empresas podem optar por aproveitar o caminhão de entrega de materiais para enviar os materiais retornados. Desta forma a logística direta e reversa se sobrepõem para diminuir o número de rotas dos veículos e economizar combustível, o que pode diminuir o índice de emissão de carbono na atmosfera. Saber a emissão de carbono durante o transporte dos resíduos é importante para que se busque meios para diminuir este valor. O uso de combustíveis menos poluentes é uma solução, como o biodiesel, que possui uma emissão de gases do efeito estufa 11,2 vezes menor do que o diesel (Gomes; Faria \& Dallemole, 2010) e uma redução de 27\% nas emissões de CO2 em comparação com o diesel (Qi; Geng; Chen; Bian; Liu \& Ren, 2009).

As compras verdes, de produtos projetados para a LR, não eram uma preocupação da empresa até o momento. Mas este indicador pode influenciar os demais, pois estes produtos facilitam a sua reutilização, reciclagem e/ou remanufatura. Desta forma, é importante que se tenha atenção no momento das compras e que se busque deixar este indicador o mais próximo de 100\% possível. As compras verdes podem aumentar a reutilização de materiais. A construtora aqui apresentada reutiliza todos os seus materiais sempre que possível e quando há sobra de materiais eles são guardados e 
utilizados em outras obras ou na manutenção dos prédios já entregues. Esta é uma prática a ser adotada por outras empresas pois diminui a geração de resíduos e diminui os custos com compra de novos materiais.

A empresa não sabe quanto capital foi investido para a implantação da $L R$, pois esta aconteceu aos poucos como forma de se adaptar as legislações vigentes. Como forma de incentivar a adesão por parte dos funcionários na gestão dos resíduos e na $L R$, todo o lucro com a venda de materiais para empresas de reciclagem é revertido para compra de prêmios para os funcionários a serem sorteados na festa de fim de ano da empresa. Assim, a empresa utiliza o viés social da sustentabilidade da sua LR, que no ano de 2017 arrecadou R\$4.500,00. Deste modo, não foi possível calcular o indicador de retorno de investimento.

É preciso que a empresa possua maior controle dos resíduos quanto a sua armazenagem correta e quanto ao volume que sai da empresa e é encaminhado para o seu destino final. Atualmente os resíduos só são pesados quando chegam na empresa de reciclagem ou ao fornecedor após o retorno para fins econômicos. Quanto a conscientização dos funcionários a empresa faz treinamento interno com todos os funcionários, que devem separar os resíduos já no seu local de trabalho, assim que são gerados, para que sejam recolhidos e já armazenados nas suas devidas baias. Falta receber feedback dos funcionários quanto a adesão a gestão de resíduos e a efetividade dos treinamentos.

A respeito da satisfação dos clientes, sugerimos a empresa a fazer uma pesquisa de satisfação com seus clientes e incluir este indicador na pesquisa. Os indicadores de satisfação dos clientes e conscientização dos colaboradores auxiliam na percepção do quão envolvida está a sociedade e o impacto das ações de LR na sociedade.

De forma geral, a empresa conseguiu bons resultados, obtendo o valor de 83,33\% no indicador geral da LR. Este valor tende a mudar quando as atividades que não foram incluídas no seu cálculo forem controladas e acrescentadas. Sugerimos que a empresa tome controle destas atividades e acrescente estes valores nos indicadores para ter um valor mais real. As atividades que a empresa realiza e tem controle são bem administradas e necessitem de algumas melhorias, como:

- Procurar por produtos verdes, que facilitam a LR e por parcerias com seus fornecedores para devolver seus resíduos e conseguir crédito na próxima compra;

- Ter uma balança para controle da quantidade de resíduos que saem da empresa;

- Utilizar combustíveis com menor fator de emissão de CO2 ou buscar por meios de transporte com menor taxa de emissão;

- Aderir a questões envolvendo a gestão de resíduos e a LR na pesquisa de satisfação dos clientes e dos funcionários; e 
- Ter controle do indicador financeiro da LR, como os gastos com as práticas reversas e o valor dos benefícios gerados.

Quanto as certificações, a empresa não conhece nenhum dos selos citados neste artigo e possui a certificação de qualidade ISO 9001 a 17 anos. Segundo os gestores, algumas questões a respeito da gestão de resíduos são abordadas na auditoria da ISO 9001, mas não em sua totalidade. Atualmente a empresa não demonstrou interesse em adotar alguma certificação ambiental, mas julgou interessante estudá-las para alguma necessidade futura.

O modelo proposto auxilia em alguns pontos das certificações. Dentro do selo LEED o modelo abrange as dimensões: um (localização e transporte) com indicadores que medem os desperdícios no transporte e a sua emissão de carbono; cinco (material e recursos) com os indicadores de compras verdes, reutilização e aproveitamento dos materiais; dois (sustentabilidade do local) e seis (qualidade do ambiente interno) ao medir a satisfação dos clientes e dos funcionários e a correta armazenagem dos materiais. Quanto ao selo AQUA, são compreendidas pelo modelo a categoria 2, com o indicador a respeito das compras verdes; e a categoria 6, que engloba os indicadores da área de gestão de resíduos. Para o selo Casa Azul, o modelo aborda a categoria 4, sobre a conservação de recursos naturais, com os indicadores de compras verdes, reutilização e aproveitamento de materiais.

Como forma de demonstrar a aplicabilidade do modelo, os indicadores gerais presentes nas Equações 1, 2, 3 e 4 são apresentados e aplicados como a média dos valores obtidos em cada indicador. Para uma melhor adaptação a estratégia de cada empresa está média pode ser ponderada por cada gestor para que os valores tenham maior relevância para a gestão. Esta ponderação depende do objetivo de cada empresa.

\section{Conclusão}

A logística é uma área em destaque dentro das organizações por agregar valor ao produto/serviço. A LR é uma parte da logística, responsável pelo retorno dos materiais consumidos a partir do consumidor até a sua origem, com intuito de dar uma destinação correta ao mesmo. A LR pode trazer diversos benefícios para as empresas que adotam esta prática, sejam eles econômicos, ambientais e/ou sociais, basta que sejam bem implementados e bem administrados. A avaliação de desempenho auxilia na gestão da LR e aponta as atividades que necessitam de ações de melhoria. Este artigo propôs um modelo para a avaliação do desempenho da LR na construção civil, um setor com grande produção de resíduos, que merece atenção dos pesquisadores quanto a LR e a manutenção da mesma.

O modelo aqui desenvolvido abrange a LR dentro da logística externa, da logística interna e na gestão de resíduos, e apresenta indicadores para medir cada uma das atividades envolvidas. Sua 
aplicação auxilia ainda para a implementação de certificações verdes e uma melhor gestão das atividades de compras, financeiro emissões, desperdícios e recursos humanos. O modelo resulta em um indicador geral da LR da empresa que auxiliar os gestores nas tomadas de decisão.

O modelo foi aplicado em uma construtora com grande atuação na região da Grande Florianópolis, em Santa Catarina, e pode ser adaptado segundo a realidade de cada empresa. Percebeuse que a empresa não possui muito controle da sua LR e necessita obter maior domínio das atividades realizadas. Dentre as atividades onde foi possível avaliar o desempenho da empresa, é necessário obter maior conhecimento quanto as compras verdes e controle das questões financeira, bem como buscar por soluções para diminuir a emissão de carbono. A utilização de combustíveis menos poluentes, como o biodiesel, foi sugerida.

O presente artigo percebeu uma carência em artigos de avaliação de desempenho da logística reversa, verde e ambiental. Devido a isso, sugere para artigos futuros a validação do modelo proposto bem como a sua aplicação em diferentes tamanhos de organizações para que assim possa classificar o desempenho geral do setor de construção civil no campo da LR. Sugere-se, ainda, o desenvolvimento de um modelo geral capaz de comparar o desempenho das empresas do setor de acordo com o seu porte, pois comparar uma empresa de grande porte com outra de pequeno porte pode gerar conflitos.

\section{Referências}

Akdağ, H. C., \& Beldek, T. (2017). Waste Management in Green Building Operations Using GSCM. International Journal of Supply Chain Management, 6(3), 174-180.

Alvarenga, D. (2017). Construção civil se retrai em 2017 e segura recuperação da economia, 2017. Disponível em: https://g1.globo.com/economia/noticia/construcao-civil-se-retrai-em-2017-esegura-recuperacao-da-economia.ghtml. Acesso em: 08 jan. 2018.

Angulo, S. C.; Zordan, S.E.; John, V. M. (2001). Desenvolvimento Sustentável e a Reciclagem de Resíduos na Construção Civil. In: IV Seminário Desenvolvimento Sustentável e a Reciclagem na construção civil - materiais reciclados e suas aplicações. São Paulo - SP.

Badenhorst, A. (2013). A framework for prioritising practices to overcome cost-related problems in reverse logistics. Journal of Transport and Supply Chain Management, 7(1), 1-10.

Ballou, R.H. (1993). Logística empresarial: transportes, administração de materiais e distribuição física. Atlas.

Bouzon, M., Govindan, K., Rodriguez, C. M. T., \& Campos, L. M. (2016). Identification and analysis of reverse logistics barriers using fuzzy Delphi method and AHP. Resources, Conservation and Recycling, 108, 182-197.

Brasil (2018). 10 Inventário nacional de emissões atmosféricas por veículos automotores rodoviários. Disponível em: 
http://www.mma.gov.br/estruturas/163/_publicacao/163_publicacao27072011055200.pdf. Acesso em: 09 fev. 2018.

Butzer, S., Schötz, S., Petroschke, M., \& Steinhilper, R. (2017). Development of a performance measurement system for international reverse supply chains. Procedia CIRP, 61, 251-256.

Cancelli, D. M., \& Dias, N. L. (2015). BRevê: uma metodologia objetiva de cálculo de emissões para a frota de veículos brasileira. Engenharia Sanitária e Ambiental, 1(1).

Carter, C., \& Ellram, L. M. (1998) Journal of Business Logistics; Hoboken.

CBCS - Conselho Brasileiro De Construção Sustentável (2014). Aspectos da Construção Sustentável no Brasil e Promoção de Políticas Públicas. Brasil.

Chileshe, N., Rameezdeen, R., Hosseini, M. R., \& Lehmann, S. (2015). Barriers to implementing reverse logistics in South Australian construction organisations. Supply chain management: an international journal, 20(2), 179-204.

Corrêa, L., R. (2009). Sustentabilidade na construção civil. (Monografia de especialização em construção civil). Escola de engenharia, Universidade Federal de Minas Gerais (UFMG), Brasil.

Crawford, P., \& Bryce, P. (2003). Project monitoring and evaluation: a method for enhancing the efficiency and effectiveness of aid project implementation. International journal of project management, 21(5), 363-373.

Elkington, J. (1994). Towards the sustainable corporation: Win-win-win business strategies for sustainable development. California management review, 36(2), 90-100

Esin, T., \& Cosgun, N. (2007). A study conducted to reduce construction waste generation in Turkey. Building and Environment, 42(4), 1667-1674.

European Commission (2018). LIFE \& the Circular economy. Luxembourg: European Union, 2017. 104 p. Disponível em:

$<$ http://ec.europa.eu/environment/life/publications/lifepublications/lifefocus/documents/circ ular_economy.pdf>. Acesso em: 08 jan. 2018.

Gomes, V. M.; Fariia, A.M. de M., \& Dallemole, D. (2010). Estimativa da Emissão de Gás Carbônico Derivado do Consumo de Combustíveis do Brasil e Mato Grosso entre 2000 e 2008: Identificando Contenção de Externalidades Negativas e Tendências de Ajustamento a uma Economia de Baixo Carbono. V Encontro Associação Nacional de Pós-Graduação e Pesquisa em Ambiente e Sociedade, Florianópolis.

Ibama (2018). Metodologia Nota Verde. 2018. Disponível em:

https://servicos.ibama.gov.br/ctf/publico/pop_up_nota_verde.html. Acesso em 15 fev. 2018.

John, W. M., \& Prado, R. T. A. (2010). Boas práticas para habitação mais sustentável.

Leed. (2018). Disponível em: https://www.usgbc.org/credits. Acesso em: 06 fev. 2018.

Leite, P. R. (2002). Logística reversa: nova área da logística empresarial. Revista Tecnologística, maio. 
MENDES GRÜNBERG, P. R., FARIAS DE MEDEIROS, M. H., \& TAVARES, S. F. (2014). Certificação ambiental de habitações: comparação entre LEED for Homes, Processo AQUA e Selo Casa Azul. Ambiente \& Sociedade, 17(2).

Miguel, P.A.C., Fleury, A.; Mello, C.H.P; Nakano, D.N.; Lima, E.P.; Turrioni, J.B.; Ho, L.L.; Morabito, R.; Martins, R.A.; Sousa, R..; Costa, S.E.G., \& Pureza, V. (2012). Metodologia de Pesquisa em Engenharia de Produção e Gestão de Operações. 2. ed. Editora Campus.

Neely, A.; Gregory, M., \& Platts, K. (2005) Performance measurement system design: A literature review and research agenda. International Journal of Operations \& Production Management, v. 25, n. 12, p.1228-1263.

Prakash, C., Barua, M. K., \& Pandya, K. V. (2015). Barriers analysis for reverse logistics implementation in Indian electronics industry using fuzzy analytic hierarchy process. Procedia-Social and Behavioral Sciences, 189, 91-102.

Processo Aqua (2016). Guia prático do referencial de avaliação da qualidade ambiental do edifício. Brasil: FCAV e Cerway.

Qi, D. H., Geng, L. M., Chen, H., Bian, Y. Z., Liu, J., \& Ren, X. C. (2009). Combustion and performance evaluation of a diesel engine fueled with biodiesel produced from soybean crude oil. Renewable Energy, 34(12), 2706-2713.

Rodrigue, J. P., Slack, B., \& Comtois, C. (2008). Green logistics. In Handbook of logistics and supplychain management (pp. 339-350). Emerald Group Publishing Limited.

Rogers, D. S., \& Tibben-Lembke, R. S. (1999). Going backwards: reverse logistics trends and practices (Vol. 2). Pittsburgh, PA: Reverse Logistics Executive Council.

Sarkis, Zhu \& Lai, 2011. An organizational theoretic review of green supply chain management literature. International Journal of Production Economics, 130(1), 1-15.

Schneider, D. \& Philippi Jr., A. (2004). Gestão pública de resíduos da construção civil no município de São Paulo. Ambiente Construído, 4(2), 21-32.

Shaik, M. N., \& Abdul-Kader, W. (2013). Transportation in reverse logistics enterprise: A comprehensive performance measurement methodology. Production Planning \& Control, 24(6), 495-510.

Shaik, M., \& Abdul-Kader, W. (2011, January). A Comprehensive Performance Measurement Framework for Reverse Logistics Enterprise. In IIE Annual Conference. Proceedings (p. 1). Institute of Industrial and Systems Engineers (IISE).

Singh, R. K., \& Acharya, P. (2014). Performance evaluation of supply chain management systems: a critical review of literature. International Journal of Procurement Management, 7(2), 201-218.

Souza, E. D. de; Hammes, G., \& RODRIGUEZ, C.M.T (2017). Barreiras na implementação da Logística Reversa nas empresas catarinenses. In: 3o Congresso Internacional de Logística e Operações do IFSP - Campus Suzano, Suzano, São Paulo.

Trochu, J., Chaabane, A., \& Ouhimmou, M. (2018). Reverse logistics network redesign under uncertainty for wood waste in the CRD industry. Resources, Conservation and Recycling, 128, $32-47$. 
Valente, J. P. (2009). Certificações na construção civil: comparativo entre LEED e HQE. Rio de Janeiro. 